\title{
Satellite Based Downward Long Wave Radiation by Various Models in Northeast Asia
}

\author{
Chanyang Sur ${ }^{1}$, Hyunwoo Kim² ${ }^{2}$ and Minha Choi ${ }^{3, *}$ \\ ${ }^{1}$ Department of Civil and Environmental Engineering, Hanyang University, Seoul, Republic of Korea \\ ${ }^{2}$ Department of Environmental and Energy Engineering, Anyang University, Anyang, Republic of Korea \\ ${ }^{3}$ Water Resources and Remote Sensing Laboratory, Department of Water Resources, Graduate School of Water Resources, \\ Sungkyunkwan University, Suwon, Republic of Korea
}

Received 4 June 2014, revised 14 August 2014, accepted 15 August 2014

\begin{abstract}
Satellite-based downward long wave radiation measurement under clear sky conditions in Northeast Asia was conducted using five well-known physical models (Brunt 1932, Idso and Jackson 1969, Brutsaert 1975, Satterlund 1979, Prata 1996) with a newly proposed global $R_{l d}$ model (Abramowitz et al. 2012). Data from two flux towers in South Korea were used to validate downward long wave radiation. Moderate resolution imaging spectroradiometer (MODIS) atmospheric profile products were used to develop the $R_{l d}$ models. The overall root mean square error (RMSE) of MODIS $R_{l d}$ with respect to two ecosystem-type flux towers was determined to be $\approx 20 \mathrm{~W} \mathrm{~m}^{-2}$. Based on the statistical analyses, MODIS $R_{l d}$ estimates with Brutsaert (1975) and Abramowitz et al. (2012) models were the most applicable for evaluating $R_{l d}$ for clear sky conditions in Northeast Asia. The Abramowitz $R_{l d}$ maps with MODIS $T_{a}$ and $e_{a}$ showed reasonable seasonal patterns, which were wellaligned with other biophysical variables reported by previous studies. The MODIS $R_{l d}$ map developed in this study will be very useful for identifying spatial patterns that are not detectable from ground-based $R_{l d}$ measurement sites.
\end{abstract}

Key words: Downward long wave radiation, Moderate resolution imaging spectroradiometer, Air temperature, Vapor pressure, Brutsaert, Abramowitz

Citation: Sur, C., H. Kim, and M. Choi, 2014: Satellite based downward long wave radiation measurement using various models in Northeast Asia. Terr. Atmos. Ocean. Sci., 25, 893-902, doi: 10.3319/TAO.2014.08.15.01(Hy)

\section{INTRODUCTION}

Downward long wave radiation $\left(R_{l d}\right)$ is one of the most essential components of global scale energy budget research (Duarte et al. 2006). In principle, it substantially influences net radiation and evapotranspiration (ET), which are critical factors in understanding surface energy distribution, hydrological cycles and water resource management at various scales (Niemelä et al. 2001; Bastiaanssen et al. 2005; Allen et al. 2007; Choi et al. 2008; Ryu et al. 2008). The $R_{l d}$ is mainly generated by sunlight absorption by carbon dioxide, ozone molecules and cloud water droplets in the atmosphere, along with the absorption of upward thermal radiation emitted by the surface (Idso and Jackson 1969; Mölders et al. $2008) . R_{l d}$ can be measured directly using a pyrgeometer (Duarte et al. 2006). However, this instrument is expensive, difficult to use, and not fully incorporated into the suite of

\footnotetext{
* Corresponding author

E-mail:mhchoi@skku.edu
}

normal atmospheric sensors in automated weather stations (Duarte et al. 2006; Choi et al. 2008; Kruk et al. 2010). For this reason, radiative models established using easily measurable data (i.e., air temperature and actual vapor pressure) have been commonly used to obtain $R_{l d}$.

Many models that cover both clear and cloudy skies exist from complex radiative transfer models to simple empirical models (Duarte et al. 2006). Radiative transfer models include low resolution atmospheric transmittance (LOWTRAN) (Kneizys et al. 1983), moderate resolution atmospheric transmittance (MODTRAN) (Berk et al. 1998), Streamer (Key and Schweiger 1998), and Monte-Carlo code for the physically correct tracing of photons in cloudy atmospheres (MYSTIC) (Mayer et al. 1998). These models may describe the emission and absorption processes of $R_{l d}$ in the atmosphere more precisely than simpler models. A recently introduced model for $R_{l d}$ estimation using artificial neural networks based on the nonlinearity between long wave radiation and satellite-driven 
brightness temperatures is notable compared to other models (Liu et al. 1997). Even if complicated models can estimate $R_{l d}$ more accurately, they require more data, such as temperature, humidity profiles and aerosols that are not often available at the sites (Duarte et al. 2006).

Simple models are therefore more readily applicable to local temperature and humidity atmospheric profiles characteristics (Prata 1996; Kjaersgaard et al. 2007; Choi et al. 2008; Kwon and Choi 2011). Brutsaert's (1975) and Prata's (1996) equations, which are based on the StefanBoltzman law with different physical parameterizations of the emissivity term, are typically used to estimate $R_{l d}$ under relatively homogeneous climate and topography conditions (Prata 1996; Sridhar and Elliott 2002; Duarte et al. 2006; Kjaersgaard et al. 2007; Choi et al. 2008; Ryu et al. 2008; Jang et al. 2009).

$R_{l d}$ estimations from specific local sites are not sufficient for larger scale representations due to the spatiotemporal heterogeneity of $R_{l d}$ (Kjaersgaard et al. 2007). A remote sensing technique has been a promising tool to address this issue. Diak et al. (2000) employed the satellite data retrieved from a geostationary operational environmental satellite (GOES) to estimate $R_{l d}$ under all sky conditions for agricultural applications. Wang and Liang (2009) employed linear and nonlinear models to estimate instantaneous clearsky $R_{l d}$ using a moderate resolution imaging spectroradiometer (MODIS). In addition, Bisht and Bras (2010) employed MODIS data to estimate $R_{l d}$ in Southern Great Plains.
The main objective of this study is to build a map of downward long wave radiation $\left(R_{l d}\right)$ for Northeast Asia. To accomplish this goal the most appropriate $R_{l d}$ equation for clear sky conditions was sought from among six wellknown empirical or physical equations (Brunt 1932; Idso and Jackson 1969; Brutsaert 1975; Satterlund 1979; Prata 1996; Abramowitz et al. 2012). Data from two South Korean flux tower measurements were used to validate the downward long wave radiation spatial distributions.

\section{MATERIALS AND METHODS}

\subsection{Study Site and Ground Measurement Data}

Two flux tower sites in South Korea were selected to validate the MODIS-based $R_{l d}$ algorithm. The two flux tower sites, Seolmacheon (SMK) and Cheongmicheon Farmland (CFK), are located in the mid-western area of the Korean Peninsula (Table 1 and Fig. 1). The dominant land covering the SMK site is mixed forest and the elevation from sea level is $293 \mathrm{~m}$. Several oak species and some maple trees are commonly found in this area. The average canopy height is approximately $15 \mathrm{~m}$. The tree ages range from 20 - 40 years. The radiation components were measured at a height of $18.05 \mathrm{~m}$ above the ground using a Kipp and Zonen CNR1 radiometer (Kipp and Zonen, Netherlands), while the air temperature and vapor pressure were measured at a height of $19 \mathrm{~m}$ above the ground using eddy covariance instruments (SAT-540 ultrasonic anemometer, KAIJO, Japan and

Table 1. Site descriptions of two flux towers in South Korea.

\begin{tabular}{ccccccc}
\hline ID & Sites & Latitude/Longitude & Land cover & Altitude (m) & Canopy height (m) & Age (year) \\
\hline SMK & Seolmacheon & $37.94^{\circ} \mathrm{N} / 126.95^{\circ} \mathrm{E}$ & Mixed forest & 293 & 15 & $20-40$ \\
CFK & Cheongmicheon & $37.16^{\circ} \mathrm{N} / 126.65^{\circ} \mathrm{E}$ & Rice paddy & 141 & 1 & Annual plant \\
\hline
\end{tabular}

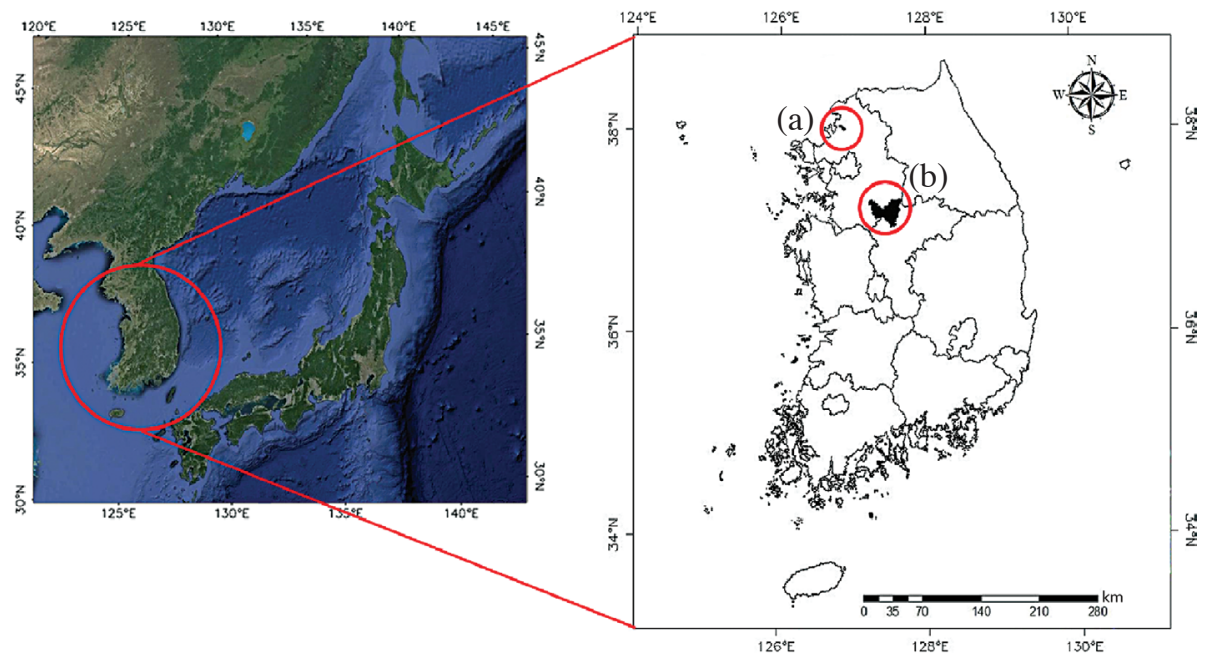

Fig. 1. Study area. (a) SMK site, (b) CFK site. 
LI-7500 open-path, LI-COR, USA, respectively). Both sets of measurements were acquired at 30 minute intervals on average. The CFK site is located on farmland with complex land coverage and an elevation of $141 \mathrm{~m}$. The average canopy height is approximately $1 \mathrm{~m}$. The radiation components were measured at a height of $10 \mathrm{~m}$ above the ground using a Net radiometer (CRN2, Kipp and Zonen, Netherlands), while the air temperature and vapor pressure were measured at a height of $10 \mathrm{~m}$ above the ground using an eddy covariance system (RM81000 3D sonic anemometer, RMYoung, USA and KH20 hygrometer, Campbell Sci., USA, respectively). Both sets of measurements were acquired at 30 minute intervals on average. The flux tower measurements include key meteorological variables, such as radiation and precipitation with continuous flux variables such as water and energy.

\subsection{Satellite Data}

MODIS has been widely used for energy balance studies because it provides a solid guideline on spatiotemporally continuous information over the surface of the Earth (Tang and Li 2008; Jang et al. 2009). MODIS data from the Terra spacecraft (10:30 overpass) were used to estimate $R_{l d}$ using equations. Among all existing MODIS products provided by the National Aeronautics and Space Administration (NASA), the atmospheric profile product MOD07, which includes air and dew point temperatures, was selected for this study. The spatial resolution of MOD07 is $25 \mathrm{~km}^{2}$. It provides instantaneous geophysical variables with intermediate resolution, such as latitude, longitude, air and dew-point temperature, surface pressure, total precipitable water vapor, solar zenith angle, and brightness temperature (Seemann et al. 2003). From among these datasets, air temperature and dew-point temperature retrieved from 2008 data were used in this study. To select the number of clear sky days used for $R_{l d}$ models, we counted the number of $1 \mathrm{~km}^{2}$ clear pixels within a $25 \mathrm{~km}^{2}$ pixel in the MOD07 atmospheric profile product (Ryu et al.2008). The data points considered to be "perfect" clear sky days (having 25 clear pixels) were only selected for the analysis. The long wave radiation was then retrieved from the air and dew-point temperatures at the bottom of the valid layer among twenty vertical atmospheric pressure levels. The Clausius-Clapeyron equation was used to calculate the actual water vapor pressure described as

$e_{a}=6.108 \times \exp ^{\left[17.27 \times T_{d} /\left(T_{d}+237.3\right)\right]}$

where $e_{a}$ is MODIS-driven actual water vapor pressure at screen level $(h P a)$, and $T_{d}$ is the dew point temperature $\left({ }^{\circ} \mathrm{C}\right)$.

\subsection{Downward Long Wave Radiation $\left(\boldsymbol{R}_{l d}\right)$ Models}

The general form of the $R_{l d}$ equation is:

$R_{l d}=\varepsilon_{a} \sigma T_{a}^{4}$

where $\varepsilon_{a}$ is the atmospheric emissivity, $\sigma$ is the StefanBoltzman constant $\left(\mathrm{W} \mathrm{m}^{-2} \mathrm{~K}^{-4}\right)$, and $T_{a}$ is the air temperature $(\mathrm{K}) . R_{l d}$ modeling was dependent mainly on how to calculate $\varepsilon_{a}$, which is typically determined by the $T_{a}$ and $e_{a}$ near the land surface (Choi et al. 2008). The five clear sky-based models for $R_{l d}$ derived from the observed radiation flux and transfer theory were selected (Table 2). We adopted a new global $R_{l d}$ model from Abramowitz et al. (2012). Their developed equation is described as:

$f(e, T)=3.1 e+2.84 T-522.5$

where $e$ is the actual vapor pressure (hPa) and $T$ is the air temperature $(\mathrm{K})$. The main property of the Abramowitz $R_{l d}$ model is that cloudy variables might be redundant in estimating all-sky $R_{l d}$ if a functional frame of $R_{l d}=f$ (temperature, surface vapor pressure) is reasonably chosen.

\section{RESULTS AND DISCUSSION}

\subsection{Spatio-Temporal Variations of $\boldsymbol{R}_{l d}$ in Northeast Asia}

The spatio-temporal variations of instantaneous $R_{l d}$ based on the Abramowitz model with MODIS input data

Table 2. The six $R_{l d}$ models with original parameters.

\begin{tabular}{ll}
\hline \multicolumn{1}{c}{ Downward Longwave Radiation } & \multicolumn{1}{c}{ References } \\
\hline$R_{l d}=\left(0.605+0.048 e_{a}^{1 / 2}\right) \sigma T_{a}^{4}$ & Brunt 1932 \\
$R_{l d}=\left\{1-0.26 \exp \left[-7.77 \times 10^{-4}\left(273-T_{a}\right)^{2}\right]\right\} \sigma T_{a}^{4}$ & Idso and Jackson 1969 \\
$R_{l d}=1.24\left(e_{a} / T_{a}\right)^{0.14} \sigma T_{a}^{4}$ & Brutsaert 1975 \\
$R_{l d}=\left\{1.08\left[1-\exp \left(-e_{a}^{T_{a} / 2016}\right)\right]\right\} \sigma T_{a}^{4}$ & Satterlund 1979 \\
$R_{l d}=\left(1-\left[1+46.5\left(e_{a} / T_{a}\right)\right] \exp \left\{-\left[1.20+139.5\left(e_{a} / T_{a}\right)\right]^{1 / 2}\right\}\right) \sigma T_{a}^{4}$ & Prata 1996 \\
$R_{l d}=3.1 e_{a}+2.84 T_{a}-522.5$ & Abramowitz et al. 2012 \\
\hline
\end{tabular}

Note: $T_{a}$ : air temperature $(K)$ and $e_{a}$ : actual vapor pressure $(h P a)$. 
in Northeast Asia are presented in Fig. 2. We can observe that the overall $R_{l d}$ values in the growing season (from May to October) are higher (more red) than in the non-growing season. Because the most important factors regulating $R_{l d}$ values are the air temperature and water vapor pressure, as described in the model equations, it is easy to explain the appearance of the high $R_{l d}$ numbers in the "hot and humid" growing season. This seasonal $R_{l d}$ pattern in Northeast Asia was very similar to other biophysical variables such as LAI, evapotranspiration (ET), net radiation, and gross primary production (GPP) in previous reports (Kang et al. 2003; Hwang et al. 2008; Hwang et al. 2013).

One annual survey on the variation in $R_{l d}$ revealed more interesting facts. First, $R_{l d}$ values were highest in the southern coastal region from January to April and from October to December. The highest values gradually transitioned to the mid-western coastal region in May, June, July, August, and September. In contrast, the majority of the lower $R_{l d}$ numbers were distributed around the mid-eastern high mountainous areas throughout the year, although there was a minor change. The differences in $R_{l d}$ values between the mid-eastern area and southwestern coastal region reached up to $400 \mathrm{~W} \mathrm{~m}^{-2}$ in September and October. The possible cause for this variation may have been the low level of turbulent Yellow Sea flux (Na et al. 1999). However, further study is required beyond the scope of this paper.

Satellite $R_{l d}$ maps successfully described the geophysical information for the high regions. In fact, the information presented in the above paragraph would not exist if we employed only the ground-measured methods. This is because the Sorak Mountain altitude is $1708 \mathrm{~m}$, among other reasons. $R_{l d}$ values in the mountainous region were well-resolved (from $\approx 100-300 \mathrm{~W} \mathrm{~m}^{-2}$ ) in all twelve figures using satellite measurements. We could reasonably match that figure with the altitude morphology of Northeast Asia. The blue color location closely overlapped with most Korean mountains in this figure; that is, $R_{l d}$ decreased as the altitude increased. Halla Mountain on Jeju Island (a large island located in the
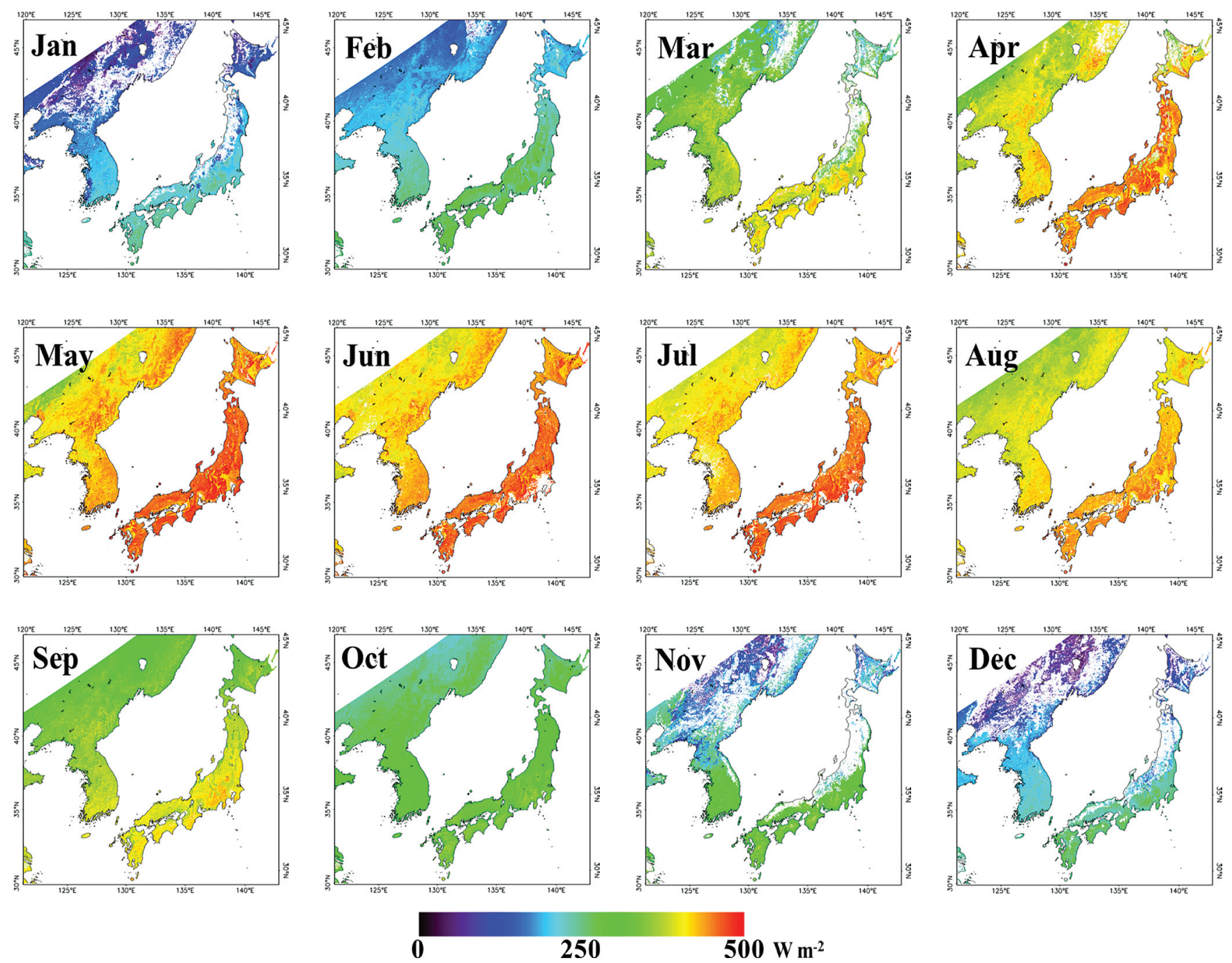

Fig. 2. Spatial distributions of $R_{l d}$ based on Abramowitz's equation with MODIS input data. 
southern part of Korea) is the highest mountain in South Korea at a height of $1950 \mathrm{~m}$. Unfortunately, severe cloud contamination hampered obtaining meaningful $R_{l d}$ images from the entire Jeju Island in November and December. Even though Halla Mountain is the highest mountain in Korea, $R_{l d}$ values were indicated as lower in the mid-eastern mountainous regions during spring and fall. The low latitude of Jeju Island and the warm Tsushima current seemed to disturb the hydrophysical resolution changes around the mountain, swamping the mountain $R_{l d}$ values with values from the surroundings. Regardless of these drawbacks, the highest $R_{l d}$ values were observed in the southern coastal areas with a low altitude, which was consistent with the study by Yang et al. (2010) on the Tibetan Plateau. Nevertheless, the maps in Fig. 2 successfully demonstrate seasonal variation as a function of altitude elevation.

\section{$3.2 R_{l d}$ from Flux Towers}

In Fig. 3 and Table $3 \mathrm{a}$, the MODIS $T_{a}$ and $e_{a}$ results are compared with ground-measured values from two flux towers located at Seolmacheon (SMK) and Cheongmicheon (CFK) sites. The MODIS-retrieved $T_{a}$ values agreed well with the flux tower measurements. The regression slope, $\mathrm{R}^{2}$, bias, and root mean square error (RMSE) values were
$0.90,0.91,-3.29$, and 4.27 at the SMK site, and 0.95, 0.94, -0.49 , and 1.99 at the CFK site, respectively. In the case of actual vapor pressure $\left(e_{a}\right)$, the regression slope, intercept, $\mathrm{R}^{2}$, Bias, and RMSE were $0.67,2.70,0.84,-1.20$, and 3.31 at the SMK site. A relatively small regression slope $(0.67)$ and high intercept position (2.70) resulted in overestimation of $e_{a}$ at small values and an underestimation of $e_{a}$ for large values at this site. The MODIS-retrieved $e_{a}$ resulted in an overall overestimation at the CFK site with the regression slope, intercept, $\mathrm{R}^{2}$, bias, and RMSE values of $0.93,4.74$, $0.72,4.29$, and 4.96, respectively. The error magnitudes were generally similar to those in previous studies (Bisht et al. 2005; Ryu et al. 2008; Bisht and Bras 2010).

Ryu et al. (2008) compared MODIS air temperature $\left(T_{a}\right)$ and actual vapor pressure $\left(e_{a}\right)$ from the Terra satellite with flux tower measurements. They reported an RMSE of $2.9^{\circ} \mathrm{C}\left(T_{a}\right)$ and $4.0 \mathrm{hpa}\left(e_{a}\right)$ at Gwangneung. Using Aqua satellite data the RMSE of $T_{a}$ was $2.6^{\circ} \mathrm{C}$ and $3.2 \mathrm{hpa}$ of $e_{a}$. As shown by the data, the magnitude of the experimental errors generally corresponded to previous studies (Bisht et al. 2005; Ryu et al. 2008; Bisht and Bras 2010). One intriguing point is that the SMK site yielded a smaller "inter-instrumental" difference (i.e., RMSE) in $T_{a}$ and a larger difference in $e_{a}$ compared to the CFK site. The CFK site is located in a flat area as a possible explanation for this observation. This
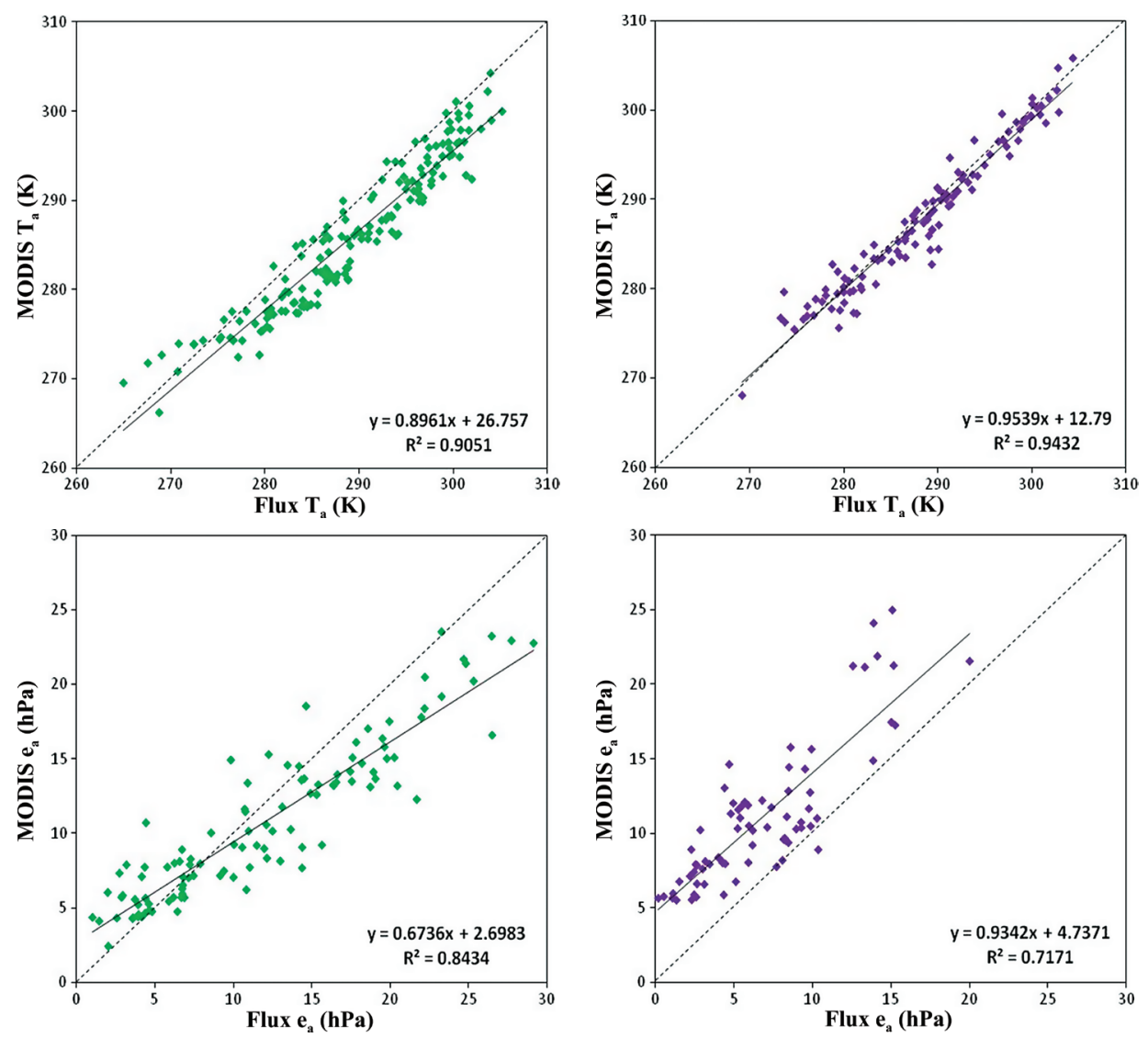

Fig. 3. Comparisons between observed and estimated meteorological variables. 
Table 3. Validations of MODIS-retrieved $T_{a}, e_{a}$, and $R_{l d}$ with flux tower measured data.

(a) Input variables $\left(T_{a}, e_{a}\right)$

\begin{tabular}{|c|c|c|c|}
\hline \multicolumn{2}{|c|}{ Parameters } & \multirow{2}{*}{$\begin{array}{c}\text { SMK } \\
0.90\end{array}$} & \multirow{2}{*}{$\begin{array}{l}\text { CFK } \\
0.95\end{array}$} \\
\hline$T_{a}(\mathrm{~K})$ & A & & \\
\hline & B & 26.76 & 12.79 \\
\hline & $\mathrm{R}^{2}$ & $0.91 *$ & $0.94 *$ \\
\hline & Bias & -3.29 & -0.49 \\
\hline & RMSE & 4.27 & 1.99 \\
\hline \multirow[t]{5}{*}{$e_{a}(\mathrm{hPa})$} & A & 0.67 & 0.93 \\
\hline & B & 2.70 & 4.74 \\
\hline & $\mathrm{R}^{2}$ & $0.84 *$ & $0.72 *$ \\
\hline & Bias & -1.20 & 4.29 \\
\hline & RMSE & 3.31 & 4.96 \\
\hline
\end{tabular}

(b) $R_{l d}$ estimations

\begin{tabular}{|c|c|c|c|}
\hline \multicolumn{2}{|c|}{ MODIS Rld models } & SMK & CFK \\
\hline \multirow[t]{5}{*}{ Brunt } & A & 0.81 & 0.91 \\
\hline & B & 40.14 & 8.00 \\
\hline & $\mathrm{R}^{2}$ & $0.86^{*}$ & $0.91 \%$ \\
\hline & Bias & -16.23 & -22.30 \\
\hline & RMSE & 28.85 & 28.30 \\
\hline \multirow[t]{5}{*}{ Brutsaert } & A & 0.91 & 0.99 \\
\hline & B & 11.75 & 14.65 \\
\hline & $\mathrm{R}^{2}$ & $0.87 *$ & $0.92 *$ \\
\hline & Bias & -13.22 & -15.71 \\
\hline & RMSE & 26.70 & 23.87 \\
\hline \multirow[t]{5}{*}{ Idso and Jackson } & A & 0.77 & 0.77 \\
\hline & B & 60.03 & 32.37 \\
\hline & $\mathrm{R}^{2}$ & $0.82 *$ & $0.77 *$ \\
\hline & Bias & -6.04 & -44.78 \\
\hline & RMSE & 27.25 & 53.30 \\
\hline \multirow[t]{5}{*}{ Prata } & A & 0.82 & 0.92 \\
\hline & B & 44.38 & 12.08 \\
\hline & $\mathrm{R}^{2}$ & $0.86^{*}$ & $0.91 *$ \\
\hline & Bias & -8.74 & -14.65 \\
\hline & RMSE & 25.36 & 22.70 \\
\hline \multirow[t]{5}{*}{ Satterlund } & A & 0.81 & 0.84 \\
\hline & B & 58.23 & 45.92 \\
\hline & $\mathrm{R}^{2}$ & $0.86^{*}$ & $0.90 *$ \\
\hline & Bias & 2.09 & -5.24 \\
\hline & RMSE & 23.72 & 19.27 \\
\hline \multirow[t]{5}{*}{ Abramowitz } & A & 0.67 & 0.79 \\
\hline & B & 114.71 & 78.62 \\
\hline & $\mathrm{R}^{2}$ & $0.88 *$ & $0.93 *$ \\
\hline & Bias & -17.03 & 10.79 \\
\hline & RMSE & 31.71 & 20.70 \\
\hline
\end{tabular}

Note: (1) $Y=A x+B(X=$ Ground measured data; $Y=$ MODIS input variables.)

(2) Data points in $G D K=326$ and $H F K=260$.

(3) *: Significant at the 0.05 probability level. enables less position-to-position variation in the temperature due to the temperature-invariant atmosphere, while the mountainous area experiences more variation in the average vapor pressure caused by the irregular and location-dependent water supply.

Figure 4 and Table $3 \mathrm{~b}$ compare the MODIS $R_{l d}$ results using five well-known models (Brunt 1932, Idso and Jackson 1969, Brutsaert 1975, Sattuerlund 1979, Prata 1996) with ground-measured values from two flux towers. Overall good agreement between the MODIS $R_{l d}$ and measured data were observed. The $\mathrm{R}^{2}$ values ranged from $0.82-0.86$ at the SMK site, and $0.77-0.91$ at the CFK site, respectively. The regression slope (A) values ranged from 0.82 for the Idso and Jackson model to 0.87 for the Brutsaert model at the SMK site, and 0.77 for the Idso and Jackson model to 0.92 for the Brutsaert model at the CFK site, respectively. In all of the above cases the CFK site showed better correlation between measurement methods presumably because it contains flat terrain that influences the downward long wave absorption compared to the forest-dominant SMK site. A positive bias value (i.e., overestimation) was observed in two cases $\left(2.09 \mathrm{~W} \mathrm{~m}^{-2}\right.$ at the SMK site from the Satterlund model, and $10.79 \mathrm{~W} \mathrm{~m}^{-2}$ at the CFK site from the Abramowitz model) among all five equations at two flux tower sites. That is, MODIS values were generally lower than groundmeasured data values, which was quite predictable considering remote-sensing interference factors such as clouds and meso/macro scale air circulation (Duarte et al. 2006; Choi et al. 2008; Tang and Li 2008).

In general, the Brutsaert model was determined to be the most applicable model considering statistical errors, A, $\mathrm{B}$, and $\mathrm{R}^{2}$ values, which were well-supported by several previous studies (Sridhar and Elliott 2002; Duarte et al. 2006; Kjaersgaard et al. 2007; Choi et al. 2008; Choi 2013). In the case of the Satterlund model the statistical errors were slightly lower than those from the Brutsaert and Prata models. However, the difference was less than $10 \%$. On the contrary, $\mathrm{B}$, and $\mathrm{R}^{2}$ values were substantially larger and the values were smaller than those from two other models at two sites (Table 3). In addition, the Prata model showed good but slightly less agreement for the same criteria. Sridhar and Elliott (2002) demonstrated that the Brutsaert model performed better than the Anderson (1954) and Idso (1981) models, whereby the RMSE and mean absolute error (MAE) values of the Brutsaert model ranged from 27.2 - 41.4, and $20.1-33.1 \mathrm{~W} \mathrm{~m}^{-2}$. Note that their RMSE values correspond to those in the present study $\left(\approx 20 \mathrm{~W} \mathrm{~m}^{-2}\right)$. Duarte et al. (2006) evaluated seven $R_{l d}$ equations for clear sky conditions using 279 days of ground-measured data from an experimental site at Ponta Grossa, Brazil. Best results were achieved with the Brutsaert model: the Bias, RMSE, MAE ( $\mathrm{W} \mathrm{m}^{-2}$ ), A and B of linear regression, and $\mathrm{R}^{2}$ values of the Brutsaert model were $12.9,15.4,13.5,0.9,42.73$, and 0.92 , respectively; these results are also close to the numbers we observed in 

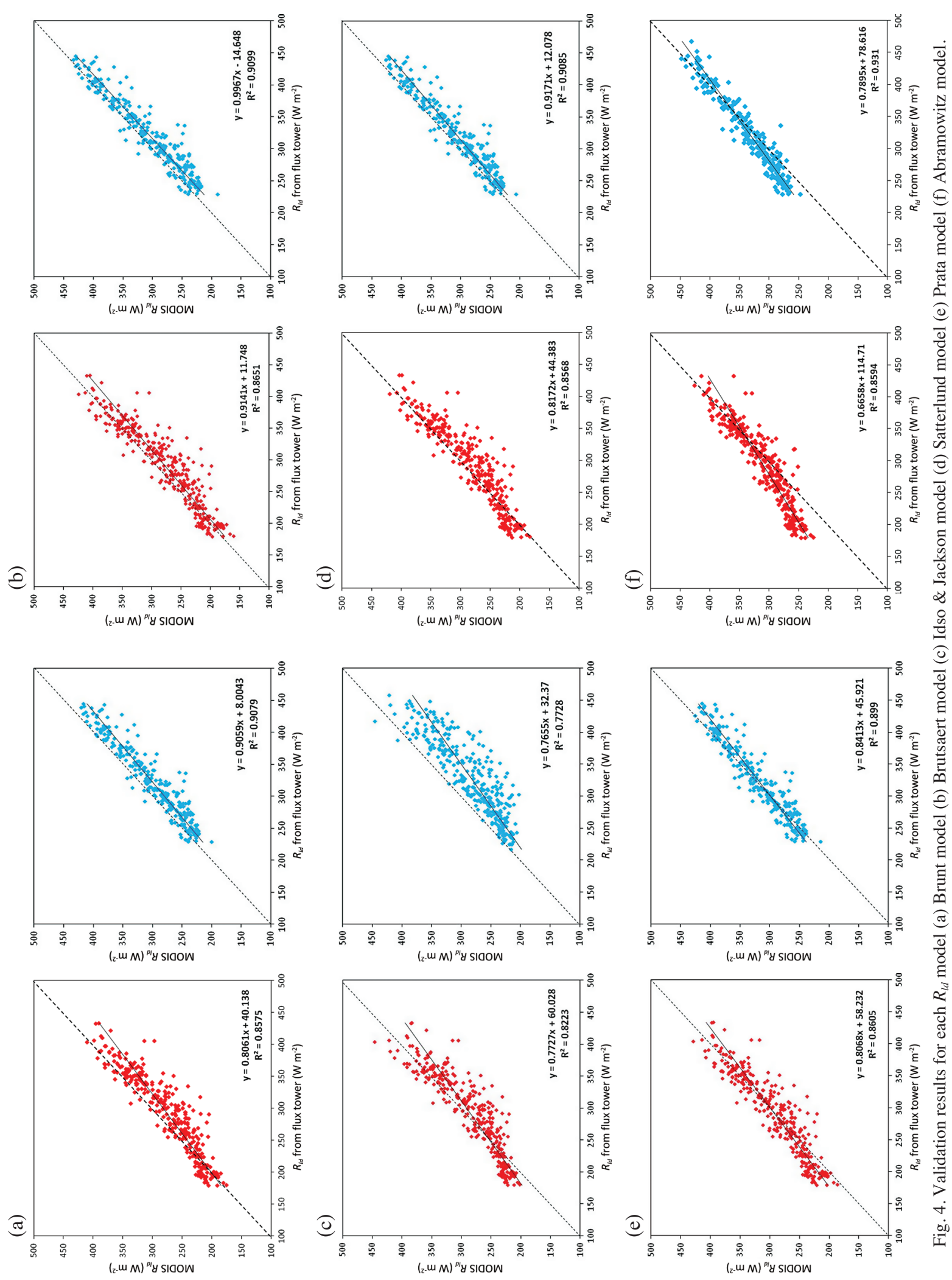
this work. Kjaersgaard et al. (2007) compared twenty $R_{l d}$ models for clear sky conditions using ground-measured air temperatures and water vapor pressure at screen height. The RMSEs ranged from $30-45 \mathrm{~W} \mathrm{~m}^{-2}$ for clear sky days. They determined that four models (Brunt 1932; Swinbank 1963; Brutsaert 1975; Prata 1996) were superior in performance to sixteen other models tested in their study. Most recently, Choi et al. (2008) tested five models for clear sky conditions, thereby demonstrating that the Brunt (1932) and Brutsaert (1975) models performed the best at eleven studied sites in Florida, USA. Based on our observations as well as on numerous aforementioned case studies, it is reasonable to acknowledge the relevance of the Brutsaert model in atmospheric long wave radiation studies.

For the present study, we evaluated a new $R_{l d}$ calculation using the Abramowitz model and compared it with ground-measured $R_{l d}$ from the two flux tower sites in South Korea. The Abramowitz model provided reasonable $R_{l d}$ results compared with the other models. The $\mathrm{R}^{2}$ values were 0.88 at the SMK site, and 0.93 at the CFK site, respectively. The regression slope A values were 0.67 at the SMK site, and 0.79 at the CFK site, respectively. The Bias and RMSE were -17.03 and $31.71 \mathrm{~W} \mathrm{~m}^{-2}$ at the SMK site, and 10.79 and $20.70 \mathrm{~W} \mathrm{~m}^{-2}$ at the CFK site, respectively. For these results the Abramowitz model demonstrated the best performance compared to the other models (Choi 2013). Choi (2013) estimated point-based daytime $R_{l d}$ by various physical or empirical models at two Korean regional flux sites and introduced performances of the Abramowitz model. The bias and RMSE were -9.5 and $29.6 \mathrm{~W} \mathrm{~m}^{-2}$ at the Gwangneung (GDK) site, and 1.3 and $28.5 \mathrm{~W} \mathrm{~m}^{-2}$ at the Haenam (HFK) site, respectively. The regression slope and intercept values were relatively lower and higher, respectively, than the other model. While Choi (2013) conducted only point-scaled $R_{l d}$, we performed satellite-based (gridded-scaled) $R_{l d}$ spatial mapping. For this reason, we conducted by this study a first step to determining the applicability of grid-scaled various $R_{l d}$ models, including the Abramowitz model, for spatial analysis in Northeast Asia.

\section{CONCLUSIONS}

Six $R_{l d}$ models for clear sky conditions were tested using MODIS input variables and climate data sets from two flux towers sites in this study. Before we evaluated the performance of these models, we validated the MODIS $T_{a}$ and $e_{a}$ with ground-measured data from flux towers. MODIS $T_{a}$ and $e_{a}$ in clear sky conditions agreed well with ground-measured data at two flux tower sites in South Korea. This result indicates that $R_{l d}$ can be estimated with remote sensingbased $T_{a}$ and $e_{a}$ with reasonable accuracy, whereas a ground measurement of $R_{l d}$ was not possible. The average RMSE of MODIS $R_{l d}$ was determined to be $\approx 20 \mathrm{~W} \mathrm{~m}^{-2}$ compared to the measured $R_{l d}$ at the flux towers sites. MODIS-retrieved
$R_{l d}$ 's based on six common equations were compared at two sites in South Korea. Based on the optimized regression slope, interception, $\mathrm{R}^{2}$, bias, and RMSE values, MODIS $R_{l d}$ estimates using Brutsaert (1975) and Abramowitz et al. (2012) models were the most applicable for describing $R_{l d}$ for clear sky conditions in South Korea, and the Abramowitz equation performed slightly better. Based on these results, we developed Abramowitz $R_{l d}$ maps with MODIS $T_{a}$ and $e_{a}$. The seasonal patterns of $R_{l d}$ values agreed well with other biophysical variables reported by previous studies. Spatial distribution of $R_{l d}$ successfully depicted the geophysical phenomena, such as the latent heat, which could not be solely explained by statistical analysis with climate datasets from flux tower sites. We strongly believe that the MODIS $R_{l d}$ map developed in this study will be very useful for estimating with reasonable accuracy other hydrological cycle and energy balancing components.

Acknowledgements This research was supported by Space Core Technology Development Program through the National Research Foundation of Korea (NRF) funded by the Ministry of Science, ICT and Future Planning (NRF2014M1A3A3A02034789). The authors send special thanks to the Hydrological Survey Center (HSC) for their data collection efforts.

\section{REFERENCES}

Abramowitz, G., L. Pouyanne, and H. Ajami, 2012: On the information content of surface meteorology for downward atmospheric long-wave radiation synthesis. Geophys. Res. Lett., 39, L04808, doi: 10.1029/2011GL050726. [Link]

Allen, R. G., M. Tasumi, and R. Trezza, 2007: Satellitebased energy balance for mapping evapotranspiration with internalized calibration (METRIC)-model. J. Irrig. Drain. Eng., 133, 380-394, doi: 10.1061/ (ASCE)0733-9437(2007)133:4(380). [Link]

Anderson, E. R., 1954: Energy-budget studies. Water-Loss Investigations: Lake Hefner Studies, Technical Report, U.S. Geological Survey Professional Paper 269, 71-119.

Bastiaanssen, W. G. M., E. J. M. Noordman, H. Pelgrum, G. Davids, B. P. Thoreson, and R. G. Allen, 2005: SEBAL model with remotely sensed data to improve water-resources management under actual field conditions. J. Irrig. Drain. Eng., 131, 85-93, doi: 10.1061/ (ASCE)0733-9437(2005)131:1(85). [Link]

Berk, A., L. S. Bernstein, G. P. Anderson, P. K. Acharya, D. C. Robertson, J. H. Chetwynd, and S. M. Adler-Golden, 1998: MODTRAN cloud and multiple scattering upgrades with application to AVIRIS. Remote Sens. Environ., 65, 367-375, doi: 10.1016/S0034-4257(98)00045-5. [Link] 
Bisht, G. and R. L. Bras, 2010: Estimation of net radiation from the MODIS data under all sky conditions: Southern Great Plains case study. Remote Sens. Environ.,114, 1522-1534, doi: 10.1016/j.rse.2010.02.007. [Link]

Bisht, G., V. Venturini, S. Islam, and L. Jiang, 2005: Estimation of the net radiation using MODIS (Moderate Resolution Imaging Spectroradiometer) data for clear sky days. Remote Sens. Environ., 97, 52-67, doi: 10.1016/j.rse.2005.03.014. [Link]

Brunt, D., 1932: Notes on radiation in the atmosphere. Q. J. R. Meteorol. Soc., 58, 389-420, doi: 10.1002/ qj.49705824704. [Link]

Brutsaert, W., 1975: On a derivable formula for long-wave radiation from clear skies. Water Resour. Res., 11, 742744, doi: 10.1029/WR011i005p00742. [Link]

Choi, M., 2013: Parameterizing daytime downward longwave radiation in two Korean regional flux monitoring network sites. J. Hydrol., 476, 257-264, doi: 10.1016/j. jhydrol.2012.10.041. [Link]

Choi, M., J. M. Jacobs, and W. P. Kustas, 2008: Assessment of clear and cloudy sky parameterizations for daily downwelling longwave radiation over different land surfaces in Florida, USA. Geophys. Res. Lett., 35, L20402, doi: 10.1029/2008GL035731. [Link]

Diak, G. R., W. L. Bland, J. R. Mecikalski, and M. C. Anderson, 2000: Satellite-based estimates of longwave radiation for agricultural applications. Agric. For. Meteorol., 103, 349-355, doi: 10.1016/S01681923(00)00141-6. [Link]

Duarte, H. F., N. L. Dias, and S. R. Maggiotto, 2006: Assessing daytime downward longwave radiation estimates for clear and cloudy skies in Southern Brazil. Agric. For. Meteorol., 139, 171-181, doi: 10.1016/j. agrformet.2006.06.008. [Link]

Hwang, K., M. Choi, S. O. Lee, and J. W. Seo, 2013: Estimation of instantaneous and daily net radiation from MODIS data under clear sky conditions: a case study in East Asia. Irrig. Sci., 31, 1173-1184, doi: 10.1007/ s00271-012-0396-3. [Link]

Hwang, T., S. Kang, J. Kim, Y. Kim, D. Lee, and L. Band, 2008: Evaluating drought effect on MODIS Gross Primary Production (GPP) with an eco-hydrological model in the mountainous forest, East Asia. Global Change Biol., 14, 1037-1056, doi: 10.1111/j.13652486.2008.01556.x. [Link]

Idso, S. B., 1981: A set of equations for full spectrum and 8to $14-\mu \mathrm{m}$ and 10.5 - to $12.5-\mu \mathrm{m}$ thermal radiation from cloudless skies. Water Resour. Res., 17, 295-304, doi: 10.1029/WR017i002p00295. [Link]

Idso, S. B. and R. D. Jackson, 1969: Thermal radiation from the atmosphere. J. Geophys. Res., 74, 5397-5403, doi: 10.1029/JC074i023p05397. [Link]

Jang, K., S. Kang, H. Kim, and H. Kwon, 2009: Evaluation of shortwave irradiance and evapotranspiration derived from Moderate Resolution Imaging Spectroradiometer (MODIS). Asia-Pac. J. Atmos. Sci., 45, 233-246.

Kang, S., S. W. Running, J. H. Lim, M. Zhao, C. R. Park, and R. Loehman, 2003: A regional phenology model for detecting onset of greenness in temperate mixed forests, Korea: An application of MODIS leaf area index. Remote Sens. Environ., 86, 232-242, doi: 10.1016/ S0034-4257(03)00103-2. [Link]

Key, J. R. and A. J. Schweiger, 1998: Tools for atmospheric radiative transfer: Streamer and FluxNet. Comput. Geosci., 24, 443-451, doi: 10.1016/S0098-3004(97)00130-1. [Link]

Kjaersgaard,J.H.,F.L.Plauborg, and S.Hansen, 2007: Comparison of models for calculating daytime long-wave irradiance using long term data set. Agric. For. Meteorol., 143,49-63, doi: 10.1016/j.agrformet.2006.11.007. [Link]

Kneizys, F. X., E. P. Shettle, W. O. Gallery, J. H. Chetwynd Jr., L. W. Abreu, J. E. A. Selby, S. A. Clough, and R. W. Fenn, 1983: Atmospheric Transmittance/Radiance: Computer Code LOWTRAN 6 Supplement: Program Listings. Air Force Geophysics Laboratory, Environmental Research Papers, No. 846, Air Force Systems Command, USAF.

Kruk, N. S.,Í. F. Vendrame, H. R. da Rocha, S. C. Chou, and O. Cabral, 2010: Downward longwave radiation estimates for clear and all-sky conditions in the Sertãozinho region of São Paulo, Brazil. Theor. Appl. Climatol., 99, 115-123, doi: 10.1007/s00704-009-0128-7. [Link]

Kwon, H. and M. Choi, 2011: Error assessment of climate variables for FAO-56 reference evapotranspiration. Meteorol. Atmos. Phys., 112, 81-90, doi: 10.1007/ s00703-011-0132-1. [Link]

Liu, Q., C. Simmer, and E. Ruprecht, 1997: Estimating longwave net radiation at sea surface from the Special Sensor Microwave/Imager (SSM/I). J. Appl. Meteorol., 36, 919-930, doi: 10.1175/1520-0450(1997)036<0919:ELNRAS>2.0.CO;2. [Link]

Mayer, B., A. Kylling, S. Madronich, and G. Seckmeyer, 1998: Enhanced absorption of UV radiation due to multiple scattering in clouds: Experimental evidence and theoretical explanation. J. Geophys. Res., 103, 31241-31254, doi: 10.1029/98JD02676. [Link]

Mölders, N., H. Luijting, and K. Sassen, 2008: Use of atmospheric radiation measurement program data from Barrow, Alaska, for evaluation and development of snowalbedo parameterizations. Meteorol. Atmos. Phys., 99, 199-219, doi: 10.1007/s00703-007-0271-6. [Link]

Na, J., J. Seo, and H. J. Lie, 1999: Annual and seasonal variations of the sea surface heat fluxes in the East Asian marginal seas. J. Oceanogr., 55, 257-270, doi: 10.1023/A:1007891608585. [Link]

Niemelä, S., P. Räisänen, and H. Savijärvi, 2001: Comparison of surface radiative flux parameterizations. 
Part I: Longwave radiation. Atmos. Res., 58, 1-18, doi: 10.1016/S0169-8095(01)00084-9. [Link]

Prata, A. J., 1996: A new long-wave formula for estimating downward clear-sky radiation at the surface. $Q$. J. R. Meteorol. Soc., 122, 1127-1151, doi: 10.1002/ qj.49712253306. [Link]

Ryu, Y., S. Kang, S. K. Moon, and J. Kim, 2008: Evaluation of land surface radiation balance derived from moderate resolution imaging spectroradiometer (MODIS) over complex terrain and heterogeneous landscape on clear sky days. Agric. For. Meteorol., 148, 1538-1552, doi: 10.1016/j.agrformet.2008.05.008. [Link]

Satterlund, D. R., 1979: An improved equation for estimating long-wave radiation from the atmosphere. Water Resour. Res., 15, 1649-1650, doi: 10.1029/ WR015i006p01649. [Link]

Seemann, S. W., J. Li, L. E. Gumley, K. I. Strabala, and W. P. Menzel, 2003: Operational retrieval of atmospheric temperature, moisture, and ozone from MODIS infrared radiances. Proc. SPIE, 4895, doi: 10.1117/12.466686. [Link]
Sridhar, V. and R. L. Elliott, 2002: On the development of a simple downwelling longwave radiation scheme. $A g$ ric. For. Meteorol., 112, 237-243, doi: 10.1016/S01681923(02)00129-6. [Link]

Swinbank, W. C., 1963: Long-wave radiation from clear skies. Q. J. R. Meteorol. Soc., 89, 339-348, doi: 10.1002/qj.49708938105. [Link]

Tang, B. and Z. L. Li, 2008: Estimation of instantaneous net surface longwave radiation from MODIS cloudfree data. Remote Sens. Environ., 112, 3482-3492, doi: 10.1016/j.rse.2008.04.004. [Link]

Wang, W. and S. Liang, 2009: Estimation of high-spatial resolution clear-sky longwave downward and net radiation over land surfaces from MODIS data. $R e$ mote Sens. Environ., 113, 745-754, doi: 10.1016/j. rse.2008.12.004. [Link]

Yang, K., J. He, W. Tang, J. Qin, and C. C. K. Cheng, 2010: On downward shortwave and longwave radiations over high altitude regions: Observation and modeling in the Tibetan Plateau. Agric. For. Meteorol., 150, 38-46, doi: 10.1016/j.agrformet.2009.08.004. [Link] 